\title{
Using Patents in Promotional Activities
}

\section{Toshihiro Tsuchihashi}

Faculty of Economics, Daito Bunka University, Tokyo, Japan

Email: tsuchihasi@ic.daito.ac.jp

How to cite this paper: Tsuchihashi, T. (2016) Using Patents in Promotional Activities. Theoretical Economics Letters, 6, 907916.

http://dx.doi.org/10.4236/tel.2016.65094

Received: August 11, 2016

Accepted: September 16, 2016

Published: September 19, 2016

Copyright $\odot 2016$ by author and Scientific Research Publishing Inc. This work is licensed under the Creative Commons Attribution International License (CC BY 4.0).

http://creativecommons.org/licenses/by/4.0/

\begin{abstract}
A traditional view of patents and patenting shows a trade-off between the benefit of appropriation and the cost of information revelation. However, firms may benefit from information revelation to consumers because patents can provide credible information about the firm's ability to develop new technologies and produce good quality products. In fact, we frequently observe that many firms use their patents for promotion in a variety of industries, including foods, cosmetics, and electronic devices. We construct a simple model to study a usage of patents in promotion activities, a promotional patent, and investigate an advantage for a firm to employ a promotional patent. We make two findings. First, we find a positive information value of a promotional patent to a high-type firm. The benefit stems from an increase in the consumers' willingness to pay in two ways. The expected valuation to the consumers increases because i) the patented innovation directly improves the product quality and ii) the promotional patent increases a likelihood of the firm to be a high type. The firm then absorbs the increase of the expected valuation. Second, the information value to the high-type firm is non-monotonic. The information value increases (decreases) with a prior probability that a firm is a high type when the prior probability is low (high).
\end{abstract}

\section{Keywords}

Patent, Information Revelation, Promotional Activity

\section{Introduction}

A traditional view of patents and patenting shows a trade-off between the benefit of appropriation and the cost of information revelation ${ }^{1}$. In fact, inventors often hesitate ${ }^{1}$ The basic concept of a patent is that a property right is granted to an inventor to exclude others from making, using, offering for sale, or selling the invention for a limited time in exchange for public disclosure of the invention when the patent is granted. In the economics literature, the optimal length and scope of patent protection have been analyzed. See, for example, Gilbert and Shapiro [1], Klemperer [2], Lerner [3], and Scotchmer [4]. 
to apply for patents because inventors' knowledge may spill over to their competitors. Horstmann et al. [5] suggest a mechanism how a firm's technical knowledge leaks to its competitor via a patenting behavior, and study the trade-off of patenting between its benefit and cost. They show that a leading firm keeps its invention confidential when patenting behavior reveals to the following firm that the following firm could profitably imitate the leading firm. Choi [6] argues that the patent system cannot provide perfect protection to innovators as empirical studies suggest, and shows that information revelation through infringement suits can be harmful for patentees. In his two-period model with costly imitation, there are two potential imitators, and the process of litigation reveals information about which competitors can profitably imitate the patentee $e^{2}$.

However, inventors may often benefit from information revelation, because patents can provide credible information about inventors' attributes, which are hardly observable to outsiders, thereby relieving information asymmetry (Long [10]). Mann and Sager [11] show a positive correlation between patents obtained by start-up firms in the software industry and total investment, and find that a single patent brings USD 2.7 million in investment into a start-up firm from venture capitalists, suggesting that patents serve as an indicator of a firm's higher performance. They also point out that patent signals do not work well in the initial funding round and that patent values increase in the consequent rounds. Similarly, Hsu and Ziedonis [12] study a relation between firm values and patents in the semiconductor industry. Contrary to Mann and Sager [11], Hsu and Ziedonis [12] show that in earlier funding stages, when investors face uncertainty about the firm's performance, patents serve well as an indicator of the firm's performance, leading to more investments into the firm.

This paper suggests a new aspect of the benefit from information revelation of patents ${ }^{3}$. That is, a firm can reveal its ability to develop new technologies and produce new products of good quality by using a patent for promotion. For example, Kirin Brewery Company obtained a patent, Process of Browning (Japan Patent No. 3836117), and mentioned the patented manufacturing process of its new low-malt beer in a TV commercial without explaining the technology in detail. Even if consumers do not understand how the new process contributes to the quality or taste of low-malt beer, they may believe that the taste of low-malt beer must be great just because of the fact that the new patented process is used for the product. In fact, we frequently observe that many companies use their patents for promotion in a variety of industries, including foods, cosmetics, and electronic devices. Using a questionnaire survey, the Institute of Intellectual Property in Japan shows that firms often use patents for demonstrating their advantage in performance to their competitors and their product's prominent functions to their customers (Institute of Intellectual Property [14]).

We construct a simple model to study a usage of patents in promotion activities. A

${ }^{2}$ The literature on imitation comprises many studies that look into imitation in a patent race. See, for example, Katz and Shapiro [7], Dasguputa [8], and Gallini [9].

${ }^{3}$ Patents may include the other values. Reitzig [13] uses the data set of 127 individual patents from a semiconductor company and shows a variety of aspects of the values of patent rights. 
firm with two types provides new products whose quality is either good or bad. The product quality is stochastically determined by not only the firm's type but also its production technology. The technology is either normal or innovative. The innovative technology is assumed to be protected by a patent. Consumers can observe neither the firm's type, the product quality, nor the production technology. However, if a firm employs a promotional patent, consumers become certain about the production technology because a patent provides a credible information about a firm's type to the consumers. The firm posts a take-it-or-leave-it offer as a price which is equal to the expected valuation to the consumers.

We make two findings. First, we find a positive information value of a promotional patent to the high-type firm. The benefit stems from an increase in the consumers' willingness to pay in two ways. The expected valuation to the consumers increases because i) the patented innovation directly improves the product quality and ii) the promotional patent increases a likelihood of the firm to be a high type. The firm then absorbs the increase of the expected valuation. Second, the information value to the high type firm is non-monotonic. The information value increases (decreases) with a prior probability that a firm is a high type when the prior probability is low (high).

The organization of the rest of this paper is as follows. Section 2 introduces the model and describes a situation where a firm does not use a promotional patent. Section 3 describes a situation in which a firm uses a patent in promotional activities if the firm has a patented innovation, and examines an advantage of a firm to employ a promotional patent. Section 4 provides concluding remarks and briefly discusses assumptions put in this paper. A direction of future researches is suggested as well in this section. The Appendix includes the proof of proposition.

\section{The Model}

We construct a simple model to study a usage of patents in promotion activities. A single firm introduces new products into a monopoly market with a continuum of identical consumers whose mass is normalized to one. The new products are of either good quality (henceforth, $G$ ) or bad quality (henceforth, $B$ ). Each consumer demands at most one unit, and worth of $G$ and $B$ products to consumers is one and zero, respectively. Two factors jointly and stochastically contribute to the product quality. One is the firm's type and other is a production technology the firm owns to produce the new products. However, the product quality is assumed to be unobservable to the consumers.

The firm's type is either high (henceforth, $H$ ) or low (henceforth, $L$ ). The $H$ type firm is more likely to produce the $G$ products than the $L$ type. The firm's type is the firm's private information, and that the consumers know only prior probability $r \in(0,1)$ of the firm to be an $H$ type, which is a common knowledge.

The production technology is either innovative or normal. If the firm has invented an innovative technology through $\mathrm{R} \& \mathrm{D}$ activities, it uses the process innovation to produce the new products; otherwise, it uses an existing technology (i.e., a normal 
technology). We assume a higher likelihood of innovation for the $H$ type firm. Specifically, the $L$ type firm develops the process innovation with probability $\rho \in(0,1)$ whereas the $H$ type succeeds in obtaining the innovative technology with certainty ${ }^{4}$. The process innovation enhances a probability of the firm to produce the $G$ products, but a likelihood differs between the firm's types. Table 1 shows probabilities that the firm produces the $G$ products given the firm type and the production technology. We assume naturally $q_{H} \geq q_{1} \geq q_{0}$. Thus, the firm type affects the product quality not only directly but also indirectly through a production technology the firm develops through $\mathrm{R} \& \mathrm{D}$ activities.

The firm announces a price which is a take-it-or-leave-it offer. Then, the consumers buy the products if the price is at or below the expected valuation. We employ perfect Bayesian equilibrium as a solution concept in which the consumers hold a belief about the firm's type. In any equilibrium, however, a price offered by the firm does not reveal any private information because switching a price to imitate the other type is costless for the firm and thus both types should announce the same price. Moreover, the consumers cannot observe the production technology. In other words, the consumers meet no opportunity to update their belief about the firm's type. Consequently, the firm offers a price which is equal to the expected valuation to the consumers, which is given by

$$
V(r)=r q_{H}+(1-r)\left[\rho q_{1}+(1-\rho) q_{0}\right] .
$$

The price is then accepted by the consumers.

\section{Promotional Patent}

This section considers the firm to use a patent in promotional activities. We refer to such a usage of a patent as a promotional patent. Suppose that the firm patents the process innovation (i.e., the innovative production technology) and then reveals the fact to the consumers by employing a promotional patent. As we discussed in the introduction part, employing such a promotional patent is prevalent in business situations. We assume that a promotional patent is costless because printing messages such as "patented" and patent number on product packages is inexpensive. A prominent feature of a promotional patent is to provide credible information about aproduc-

Table 1. Probability of producing $G$ products.

\begin{tabular}{ccc}
\hline Firm type & Production technology & Probability of producing $G$ products \\
\hline$H$ type & Innovative & $q_{H}$ \\
$L$ type & Innovative & $q_{1}$ \\
$L$ type & Normal & $q_{0}$ \\
\hline
\end{tabular}

${ }^{4} \mathrm{~A}$ key in the assumption is that the firm's type is positively correlated with both probabilities of producing the $G$ products and of owning the innovative technology. Assuming that the $H$ type firm obtains the innovative production technology with certainty is for the sake of simplicity. Our results do not essentially change even though we relax this assumption, unless the $L$ type firm is more likely to succeed in R \& D than the $H$ type firm. 
tion technology owned by the firm to the consumers. Thus, information asymmetry disappears in that the consumers are certain about a production technology ${ }^{5}$. In addition, the promotional patent alleviates information asymmetry about the firm's type. On observing a promotional patent, consumers believe that according to Bayes' rule, the firm is an $H$ type with probability $r /[r+(1-r) \rho]$ and an $L$ type with $(1-r) \rho /[r+(1-r) \rho]$. The expected valuation to the consumers is given by

$$
V_{1}(r)=\frac{r}{r+(1-r) \rho} \cdot q_{H}+\frac{(1-r) \rho}{r+(1-r) \rho} \cdot q_{1} .
$$

On the other hand, if the consumers do not observe a promotional patent, the firm's type faced to them is an $L$ for sure. Thus, they value the products at

$$
V_{0}(r)=q_{0} .
$$

By construction, these prices form a unique equilibrium which is described in the following proposition.

Proposition 1. Suppose that the firm employs a promotional patent whenever it patents a process innovation. In a unique equilibrium, the firm with a promotional patent offers a price which is equal to (2) whereas one without a promotional patent offers a price which is equal to (3).

Proposition 1 is by construction, thus we omit the proof. Proposition 1 suggests a benefit of a patent holder from employing a promotional patent because $V_{1}(r)>V(r)>V_{0}(r)$. The benefit is twofold. If the consumers observe a promotional patent, the expected valuation to them increases because i) the patented innovation directly improves the product quality (improvement effect) and ii) the promotional patent increases a likelihood of the $H$ type firm (discrimination effect). Then, the firm absorbs the increase of the expected valuation.

How much does the firm benefit from employing a promotional patent? In other words, hos much is a promotional patent worth to the firm? In what follows, we focus on the information value of a promotional patent to the firm. We let $S_{i}(r)$ denote an information value to an $i$ type firm. A promotional patent increases the $H$ type firm's expected payoff from $V(r)$ to $V_{1}(r)$; thus, its information value is

$$
S_{H}(r) \equiv V_{1}(r)-V(r)=\frac{(1-r)(1-\rho)}{r+(1-r) \rho}\left[r\left(q_{H}-q_{0}\right)+(1-r)\left(q_{1}-q_{0}\right) \rho\right] .
$$

Note that $S_{H}(r) \geq 0$ for any $r \in(0,1)$. The positive information value to the $H$ type firm is indeed a benefit of a patent holder discussed above; thus, the information value to the $H$ type firm increases with $q_{H}$ and $q_{1}$. On the other hand, conditional on observing a promotional patent, the consumers assign a lower posterior probability with the $H$ type firm for larger $q_{0}$ and $\rho$. First, it becomes more difficult for the $H$ type firm to distinguish itself from the $L$ type by using a promotional patent as $\rho$ increases. Second, the advantage for the $H$ type firm to distinguish itself from the $L$ type

${ }^{5} \mathrm{We}$ assume that both types of firm employ a promotional patent with probability one if they invented and then patented an innovation. Even though a promotional patent is the firm's choice, the firm should optimally employ a promotional patent because it is costless. Thus, this assumption is for the sake of simplicity. 
declines as $q_{0}$ increases. In other words, increases in $\rho$ and $q_{0}$ dilutes a discrimination effect emerged from a promotional patent; thus, $S_{H}(r)$ decreases in $q_{0}$ and $\rho$.

A promotional patent, however, may hurt the $L$ type firm because it fails to obtain the innovative technology with a positive probability and then the consumers understand its type (i.e., an $L$ type), which occurs with probability $1-\rho$. Thus, the information value to the $L$ type firm is

$$
\begin{aligned}
S_{L}(r) & \equiv \rho V_{1}(r)+(1-\rho) V_{0}(r)-V(r) \\
& =-\frac{r(1-\rho)}{r+(1-r) \rho}\left[r\left(q_{H}-q_{0}\right)+(1-r)\left(q_{1}-q_{0}\right) \rho\right] .
\end{aligned}
$$

Note that $S_{L}(r) \leq 0$ for any $r \in(0,1)$. The negative information value to the $L$-type firm is more complicated to understand. (5) implies that $S_{L}(r) \rightarrow S_{H}(r)$ as $\rho \rightarrow 1$, which may seem to indicate that the $L$ type firm can also obtain a positive profit from a promotional patent. However, in such a case, the informational function of the patent diminishes, and thus, $S_{H}(r) \rightarrow 0$ as $\rho \rightarrow 1$. To see this, suppose that the $L$ type firm also obtains a patent with probability one $(\rho=1)$. In this case, consumers can never ascertain the firm's type even if they observe a promotional patent. Furthermore, consumers understand that the firm certainly succeeds in R\&D regardless of its type. Consequently, a patent does not yield any additional profit to the firm. Moreover, from (5), the information value to the $L$ type firm decreases in $q_{H}$ and $q_{1}$ while increases with $q_{0}$ and $\rho$.

The impact of prior probability $r$ on the information value is more complicated as shown in the next proposition.

Proposition 2. The information valuation to the $H$ type firm $S_{H}(r)$ (i) decreases in prior probability of the firm to be an $H$ type $r$ for any $r \in(0,1)$ if $q_{H}-q_{1} \leq \rho\left(q_{1}-q_{0}\right)$, and (ii) increases with $r$ for $r \in(0, \bar{r})$ while decreases for $r \in(\bar{r}, 1)$ if $q_{H}-q_{1}>\rho\left(q_{1}-q_{0}\right)$, where

$$
\bar{r}=\frac{-\rho\left(q_{H}-\rho q_{1}-(1-\rho) q_{0}\right)+\sqrt{\rho\left(q_{H}-q_{1}\right)\left(q_{H}-\rho q_{1}-(1-\rho) q_{0}\right)}}{(1-\rho)\left(q_{H}-\rho q_{1}-(1-\rho) q_{0}\right)} .
$$

On the other hand, the information value to the L type firm $S_{L}(r)$ decreases in $r$ for any $r \in(0,1)$.

The proof of Proposition 2 is found in Appendix. Since $V_{1}(r)$ is strictly concave in $r$ whereas $V(r)$ is linear, $S_{H}(r)$ is also strictly concave in $r$. If a difference between $q_{H}$ and $q_{1}$ is relatively small, $\bar{r}<0$ holds so that $S_{H}(r)$ is strictly decreasing in $r$. Otherwise, it has a single peak in $(0,1)$. This case is illustrated in Figure 1.

An impact of a prior probability on the information value of a promotional patent can be divided into two parts. We focus on the information value to the $H$ type firm. By differentiating the information value $S_{H}(r)$ with respect to $r$, we have

$$
\frac{\partial S_{H}(r)}{\partial r}=-(1-\rho)\left(V_{1}(r)-V_{0}(r)\right)+(1-r)(1-\rho) \frac{\partial V_{1}(r)}{\partial r} .
$$




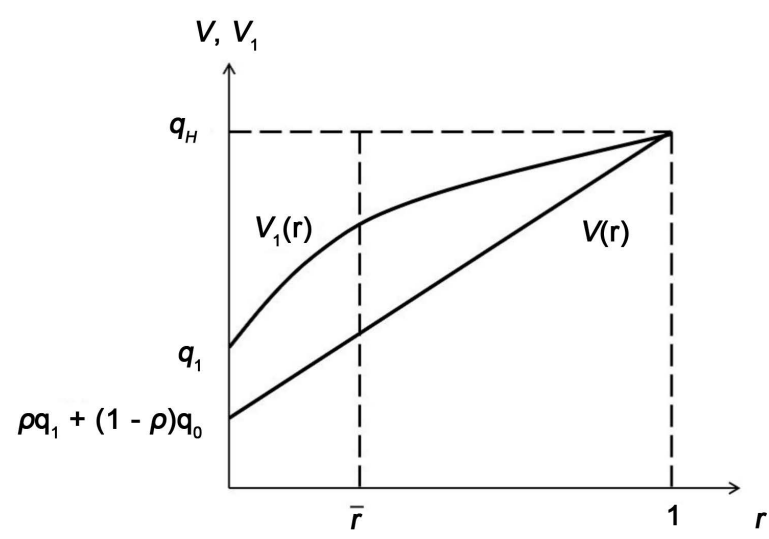

Figure 1. Expected valuations to the consumers.

The first term captures a negative impact of $r$ on the information value. As we discussed previously, by observing a promotional patent, the consumers assign a higher posterior probability on the $H$ type firm and thus increase the expected valuation to them. When a prior probability is low, observing a promotional patent has a significant impact on updating the prior probability to the consumers. However, as a prior probability increases, such an update of a prior probability becomes relatively insignificant in the sense that a difference of prior and posterior probabilities is small. That is, a function of a promotional patent to conveying an information about the firm's type becomes redundant and a discrimination effect dilutes; thus, the impact of $r$ is negative.

The second term captures a positive impact of $r$ on the information value. An increase in $r$ implies a higher likelihood of the $H$ type firm faced to the consumers. That is indeed a benefit of a patent holder as we saw above.

Proposition 2 says that if $q_{H}-q_{1} \leq \rho\left(q_{1}-q_{0}\right)$, the negative impact dominates the positive impact. However, if $q_{H}-q_{1}>\rho\left(q_{1}-q_{0}\right)$, the positive impact dominates the negative impact when $r$ is low whereas the opposite realizes when $r$ is high.

In a case of $\bar{r} \in(0,1)$, the information value to the $H$ type firm increases with $r$ up to $\bar{r}$. That is, when $r$ is small, a (small) increase in $r$ enhances a firm's profit through a promotional patent. This may seem to imply that start-up firms have a stronger incentive to obtain patents for potentially using them in promotional activities. In fact, this discussion seems consistent with recent empirical evidence. This result seems consistent with recent empirical evidence. Aoki and Spiegel [15] reports that after the American Inventor's Protection Act of 1999, in the U.S., approximately 10\% of all applicants opt-out of publication in order to keep their information confidential. However, almost all individual applicants choose to disclose, implying that information revelation of patents is important for applicants with little reputation (Graham and Hedge [16]).

\section{Concluding Remarks}

The literature emphasizes a cost of patenting that patents (or a patenting behavior) can 
leak an innovator's private information to its competitors. However, information revelation to consumers may potentially yield an advantage to a patent holder because patents provide a credible information about technical capabilities. Such a credible information alleviates information asymmetry that consumers are uncertain about the product quality. We investigate an advantage of using patents in promotional activities to which we refer as a promotional patent.

In our model, a firm with two types provides new products whose quality is either good or bad. The product quality is stochastically determined by not only the firm's type but also its production technology. The technology is either normal or innovative. The innovative technology is assumed to be protected by a patent. Consumers can observe neither the firm type, the product quality, nor the production technology. However, if the firm employs a promotional patent, the consumers become certain about the production technology. The firm posts a take-it-or-leave-it offer as a price which is equal to the expected valuation to the consumers.

We make two findings. First, we find a positive information value of a promotional patent to the high-type firm. The benefit stems from an increase in the consumers' willingness to pay in two ways. The expected valuation to the consumers increases because i) the patented innovation directly improves the product quality and ii) the promotional patent increases a likelihood of the firm to be a high type. The firm then absorbs the increase of the expected valuation. Second, the information value to the high type firm is non-monotonic. The information value increases (decreases) with a prior probability that a firm is a high type when the prior probability is low (high).

We focus on a situation in which a firm has been awarded a patent; in other words, a patenting decision is already done. Thus, our model ignores a cost of employing a promotional patent, i.e., it is a sunk cost. However, by taking a firm's patenting decision into consideration, we can show the trade-off between the cost and benefit emerged from employing a promotional patent and then can evaluate it more precisely. A more sophisticated model is required for the purpose.

This research may have an important implication for understanding why firms obtain many useless or insignificant patents. As well known, most of patented innovations have little significance measured by citations and financial returns on investment, which is shown as extreme skewness in distributions or significance (Silverberga and Verspagen [17]). However, patents create a benefit for a patent holder even if they have little contributions to technological progress and monopoly profit, which is discussed in this paper. The presence of such a benefit might solve this puzzle.

More work remains for the future research. Although a prior probability of a firm to have a high technological capability (i.e., high type) is exogenous in our model, it may be an interesting question how a firm invests in different intellectual property rights, specifically patents and trademarks, for a usage in promotional activities. As for our results, a benefit from employing a promotional patent increases with a likelihood of high type when the likelihood is small. This result may potentially imply that start-up firms can enjoy a positive synergy emerged from investing on trademarks as well as 
patents; that is, trademarks directly enhance sales regarding an increase in a likelihood of high type and indirectly benefit the start-up firms through an increase in an information value of a promotional patent. The interesting topic is, however, beyond the scope of the current work.

\section{Acknowledgements}

I am truly indebted to Reiko Aoki, Yossi Spiegel, and the attendees at the Contract Theory Workshop in Hitotsubashi University, the Lunch Seminar in Daito Bunka University, and the Spring Meeting of the Japanese Economic Association for their helpful comments and suggestions, and invaluable guidance. Any remaining errors are of course my own responsibility.

\section{References}

[1] Gilbert, R. and Shapiro, C. (1990) Optimal Patent Length and Breadth. The RAND Journal of Economics, 21, 106-112. http://dx.doi.org/10.2307/2555497

[2] Klemperer, P. (1990) How Broad Should the Scope of Patent Protection Be? The RAND Journal of Economics, 21, 113-130. http://dx.doi.org/10.2307/2555498

[3] Lerner, J. (1994) The Importance of Patent Scope: An Empirical Analysis. The RAND Journal of Economics, 25, 319-333. http://dx.doi.org/10.2307/2555833

[4] Scotchmer, S. (1999) On the Optimality of the Patent System. The RAND Journal of Economics, 30, 181-196. http://dx.doi.org/10.2307/2556076

[5] Horstmann, I., MacDonald, G. and Slivinski, A. (1985) Patents as Information Transfer Mechanisms: To Patent or (Maybe) Not to Patent. Journal of Political Economy, 93, 837858. http://dx.doi.org/10.1086/261338

[6] Choi, J. (1998) Patent Litigation as an Information-Transmission Mechanism. The American Economic Review, 88, 1249-1263.

[7] Katz, M. and Shapiro, C. (1987) R\&D Rivalry with Licensing or Imitation. American Economic Review, 77, 402-420.

[8] Dasgupta, P. (1988) Patents, Priority and Imitation or, the Economics of Races and Waiting Games. Economic Journal, 98, 66-80. http://dx.doi.org/10.2307/2233511

[9] Gallini, N. (1992) Patent Policy and Costly Imitation. The RAND Journal of Economics, 23, 53-63. http://dx.doi.org/10.2307/2555432

[10] Long, C. (2002) Patent Signals. The University of Chicago Law Review, 69, 625-679. http://dx.doi.org/10.2307/1600501

[11] Mann, R. and Sager, T. (2007) Patents, Venture Capital, and Software Start-Ups. Research Policy, 36, 193-208. http://dx.doi.org/10.1016/j.respol.2006.10.002

[12] Hsu, D. and Ziedonis, R. (2008) Patents as Quality Signals for Entrepreneurial Ventures. Academy of Management Best Paper Proceedings.

[13] Reitzig, M. (2003) What Determines Patent Value? Insights from the Semiconductor Industry. Research Policy, 32, 13-26. http://dx.doi.org/10.1016/S0048-7333(01)00193-7

[14] Institute of Intellectual Property (2010) Promotion of Intellectual Property Strategies of Companies.

[15] Aoki, R. and Spiegel, Y. (2000) Pre-grant Patent Publication and Cumulative Innovation. International Journal of Industrial Organization, 27, 333-345. 
http://dx.doi.org/10.1016/j.ijindorg.2008.10.002

[16] Graham, S. and Hegde, D. (2012) Do Inventors Value Secrecy in Patenting? Evidence from the American Inventor's Protection Act of 1999.

[17] Silverberg, G. and Verspagen, B. (2007) The Size Distribution of Innovations Revisited: An Application of Extreme Value Statistics to Citation and Value Measures of Patent Significance. Journal of Econometrics, 139, 318-339.

http://dx.doi.org/10.1016/j.jeconom.2006.10.017

\section{Appendix: Proof of Proposition 2}

Proof. By differentiating (4) with respect to $r$, we have

$$
\begin{aligned}
\frac{\partial S_{H}(r)}{\partial r}= & (1-\rho)\left(\frac{1}{r+(1-r) \rho}\right)^{2}\left(\left[(1-r)^{2} \rho-r^{2}\right]\left(q_{H}-q_{0}\right)\right. \\
& \left.-\rho(1-r)[(1+\rho)+(1-\rho) r]\left(q_{1}-q_{0}\right)\right) .
\end{aligned}
$$

Define

$$
\begin{aligned}
F(r) & =\left[(1-r)^{2} \rho-r^{2}\right]\left(q_{H}-q_{0}\right)-\rho(1-r)[(1+\rho)+(1-\rho) r]\left(q_{1}-q_{0}\right) \\
& =-(1-\rho)\left(Q_{H}-\rho Q_{1}\right) r^{2}-2 \rho\left(Q_{H}-\rho Q_{1}\right) r+\rho\left[Q_{H}-(1+\rho) Q_{1}\right],
\end{aligned}
$$

where $Q_{H}=q_{h}-q_{0}$ and $Q_{1}=q_{1}-q_{0}$. Thus, $\partial S_{H}(r) / \partial r>0$ if and only if $F(r)>0$. We observe $F(1)=-Q_{H}<0$. If $F(0)=\rho\left[Q_{H}-(1+\rho) Q_{1}\right]>0$ (or equivalently $\left.q_{H}-q_{1}>\rho\left(q_{1}-q_{0}\right)\right)$, there exists $\bar{r} \in(0,1)$ such that $\partial S_{H}(r) / \partial r>0$ for any $r \in(0, \bar{r})$. The following threshold $\bar{r}$ is a (positive) solution of $F(r, \rho)=0$ :

$$
\begin{aligned}
\bar{r} & =\frac{-\rho\left(Q_{H}-\rho Q_{1}\right)+\sqrt{\rho\left(Q_{H}-Q_{1}\right)\left(Q_{H}-\rho Q_{1}\right)}}{(1-\rho)\left(Q_{H}-\rho Q_{1}\right)} \\
& =\frac{-\rho\left(q_{H}-\rho q_{1}-(1-\rho) q_{0}\right)+\sqrt{\rho\left(q_{H}-q_{1}\right)\left(q_{H}-\rho q_{1}-(1-\rho) q_{0}\right)}}{(1-\rho)\left(q_{H}-\rho q_{1}-(1-\rho) q_{0}\right)} .
\end{aligned}
$$

On the other hand, if $F(0)=\rho\left[Q_{H}-(1+\rho) Q_{1}\right] \leq 0, F(r)<0$ for any $r \in(0,1)$. Similarly, regarding $S_{L}(r)$, by differentiating (5) with respect to $r$, we obtain

$$
\begin{aligned}
\frac{\mathrm{d} S_{L}(r)}{\mathrm{d} r} & =\frac{-(1-\rho)}{[r+(1-r) \rho]^{2}}\left[\left(r^{2}-r^{2} \rho+2 r \rho\right)\left(q_{H}-q_{0}\right)+r \rho(1-\rho-2 r+r \rho)\left(q_{1}-q_{0}\right)\right] \\
& <\frac{-(1-\rho)}{[r+(1-r) \rho]^{2}}\left[\left(r^{2}-r^{2} \rho+2 r \rho\right)\left(q_{1}-q_{0}\right)+r \rho(1-\rho-2 r+r \rho)\left(q_{1}-q_{0}\right)\right] \\
& =\frac{-(1-\rho)\left(q_{1}-q_{0}\right)}{[r+(1-r) \rho]^{2}}\left[r^{2}(1-\rho)^{2}+r \rho(3-r-\rho)\right] \\
& \leq 0 .
\end{aligned}
$$


Submit or recommend next manuscript to SCIRP and we will provide best service for you:

Accepting pre-submission inquiries through Email, Facebook, LinkedIn, Twitter, etc. A wide selection of journals (inclusive of 9 subjects, more than 200 journals)

Providing 24-hour high-quality service

User-friendly online submission system

Fair and swift peer-review system

Efficient typesetting and proofreading procedure

Display of the result of downloads and visits, as well as the number of cited articles

Maximum dissemination of your research work

Submit your manuscript at: http://papersubmission.scirp.org/ 